\title{
Effect of Glow-Discharge Air Plasma Treatment on Wettability of Synthetic Polymers
}

\author{
Ivo Krásný, Ivana Kupská, Lubomír Lapčík
}

Centre of Polymer Systems, Faculty of Technology, Tomas Bata University, Zlin, Czech.

Email: lapcik@ft.utb.cz

Received April 16 ${ }^{\text {th }}, 2012$; revised May 17 th $^{\text {t } 2012 ; ~ a c c e p t e d ~ J u n e ~} 7^{\text {th }}, 2012$

\begin{abstract}
Main aim of this study was focused on characterization of the effect of microwave air plasma treatment on wettability of synthetic polymer surfaces. Wettability of solid polymer surfaces polyethylene, polypropylene, polystyrene (PE, PP, PS) was followed as a function of plasma treatment time. For evaluation the equilibrium contact angles of wetting as well as dynamic contact angles of wetting were determined by means of sessile drop and Wilhelmy plate methods. Free surface energy (SFE) of studied samples were calculated from the experimentally determined contact angles using Fowkes and van Oss, Chaudhury and Good (vOCG) approaches. It was found that with prolonged treatment time the total surface free energy of PE was two times increased from $23 \mathrm{~mJ} / \mathrm{m}^{2}$ to $45 \mathrm{~mJ} / \mathrm{m}^{2}$ after $360 \mathrm{~s}$ plasma treatment time (calculated for W and EG as wetting liquids). Similar effect was found for all studied polymers. With respect to the dispersive and polar components of the total surface free energy the vigorous effect was found for polar component, for which it was increased from $7 \mathrm{~mJ} / \mathrm{m}^{2}$ to $20 \mathrm{~mJ} / \mathrm{m}^{2}$.
\end{abstract}

Keywords: Surface Energy; Contact Angle; Wetting; Plasma Treatment

\section{Introduction}

The interfacial properties of polymer materials are important in many technological processes such as polymer blending, wetting, coating, and the reinforcement of polymers with fibres. These are as a result of the complex synergistic effect of surface morphology, topology and chemical composition and homogeneity. The latter parameters are affected both by nano-, micro- and macroscopic structural hierarchy of the surface layer arrangement. The wetting phenomena can be accessed by contact angle measurements, which provide a better understanding of the interactions between solids and liquids, or between immiscible liquids [1,2]. Surface tension, or surface free energy is a direct manifestation of acting intermolecular forces. The surface tension on the interfaces is a very important parameter in basic physical chemistry of surfaces and in many areas of applied science and technology. That is why the surface modification plays a significant role $[1,3]$. Plasma treatment is an essential industrial process of surface modification. It is used to improve printability, wettability, bondability, biocompatibility, surface hardness, and surface heat resistance etc [4].

The surface of a solid material possesses additional free energy, but owing to the reduced molecular mobility this free energy is not directly observable, and it must be measured by indirect methods - taking advantage of contact angle measurements. There are several wellknown techniques of contact angle measurements on flat and smooth surfaces e.g. sessile drop, adhering gas bubble method and Wilhelmy plate method. The choice of particular method depends on geometry of the studied solid sample (i.e. flat plate, fibre, powder) [5-7].

Although, it is a difficult task to measure the contact angle properly on solids, a large body of reliable data has been accumulated and a vast literature exist correlating contact angle data with surface tension of solids [8].

The aim of this work is to detect an influence of plasma treatment on wettability of synthetic polymers. As an additional goal it is the verification of the accuracy of the free surface energy calculation according to Fowkes and vOCG. The latter materials are used as a basic support for attachment of molecularly oriented biopolymers, thus their proper nanometric properties and characteristics are of paramount importance.

\section{Theoretical Background}

A wide range of technological processes (e.g. cleaning, dyeing or gluing) depends on "how well" the liquid wets the surface of solid material. The term wetting and nonwetting as employed in various practical situations tend to be defined in terms of the effect desired. Usually, 
however, wetting means that the contact angle between a liquid and a solid is zero or so close to zero that the liquid spreads over the solid easily, and non-wetting means that the angle is greater than $90^{\circ}$, so that liquid tends to ball up and run off the surface easily [5].

Contact angle of wetting is a result of the balance of three vectors acting on the three-phase line among solid, liquid and vapour, namely solid surface energy $\gamma_{S V}$, liquid surface energy $\gamma_{S V}$, and solid-liquid tension $\gamma_{S L}$. This exhibits an equilibrium contact angle that can be expressed by Young's equation $[9,10]$ :

$$
\gamma_{S G}=\gamma_{S L}+\gamma_{L G} \cdot \cos \theta
$$

where $\gamma_{S G}$ and $\gamma_{L G}$ are the surface tension of a solid and the surface tension of a liquid in the equilibrium with the liquid vapour, respectively, $\gamma_{S L}$ interfacial tension between the liquid and solid, and $\theta$ is the equilibrium contact angle. It is to be pointed out that $\gamma_{S G}$ is not the surface tension of the solid ( $\gamma_{S}$ in vacuum); the difference in between is referred as the spreading pressure $\pi_{e}$ :

$$
\pi_{e}=\gamma_{S}-\gamma_{S G}
$$

An assumption was made to neglect the vapour adsorption for low surface tension solids, e.g. polymers, $\gamma_{S}=\gamma_{S G} \quad[11,12]$.

According to the Fowkes, the SFE is separated into its components:

$$
\gamma=\gamma^{C}+\gamma^{I}+\gamma^{D}+\gamma^{A B}+\gamma^{H}+\cdots
$$

where $\gamma^{D}, \gamma^{P}, \gamma^{H}, \gamma^{I}$ and $\gamma^{A B}$ are the contributions from London disperse forces, polar (Keesom forces, hydrogen-bonding forces, induction (Debye) forces, and acid-base interactions, respectively. Based on these assumptions, the following equation has been proposed, which is applicable to systems in which only dispersion forces are common to both phases:

$$
\gamma_{12}=\gamma_{1}+\gamma_{2}-2 \sqrt{\gamma_{1}^{D} \cdot \gamma_{2}^{D}}
$$

where subscripts 1 and 2 represent phases 1 and 2, respectively. Applying Equation (4) to a solid-liquid interface in given:

$$
\gamma_{S L}=\gamma_{S}+\gamma_{L}-2 \sqrt{\gamma_{S}^{D} \cdot \gamma_{L}^{D}}
$$

If $\pi_{e}$ is assumed to be small and $\gamma_{L V} \approx \gamma_{L}, \gamma_{S}$ can be eliminated by combining Equation (5) and Equation (1):

$$
\cos \theta=1-2 \sqrt{\frac{\gamma_{S V}^{D} \gamma_{L V}^{D}}{\gamma_{L V}}}
$$

Then the value of $\sqrt{\gamma_{S V}^{D}}$ can be calculated from the slop of $\cos \theta$ plotted as a function of $\sqrt{\gamma_{L V}^{D} / \gamma_{L V}}$ $[7,13,14]$.

The most recent approach was given by van Oss,
Chaudhury and Good (vOCG). According to this method, the surface tension of solid is equal to a sum of two components: $\gamma_{S}^{L W}$, connected with Lifthitz-van der Waals $(L W)$ interactions, and $\gamma_{S}^{A B}$, connected with acidbase $(A B)$ interactions. The dispersion (London), orientation (Keeson), and induction (Debye) forces, being dipolar forces, present the same type dependence on distance and are usually treated with the same combining rules. All these interactions are generally named by the van der Waals contribution $(L W)$. However, the donor-acceptor contribution to the work of adhesion (currently termed acid-base contribution) is associated with the transfer of electrons between an electron donor and an electron acceptor.

$$
\begin{aligned}
& \gamma_{S}=\gamma_{S}^{L W}+\gamma_{S}^{A B} \\
& \gamma^{A B}=2 \cdot \sqrt{\gamma_{S}^{+} \cdot \gamma_{S}^{-}}
\end{aligned}
$$

where $\gamma_{S}^{+}$and $\gamma_{S}^{-}$are components corresponding to the interactions of the Lewis acid (donor) and base (acceptor), respectively. Hence, the calculation of $\gamma_{S}$ consists in the determination of three unknown components: $\gamma_{S}^{L W}, \gamma_{S}^{+}$and $\gamma_{S}^{-}$, it is required performing contact angle measurements using different liquids, two of them being polar and one non-polar. Combining Equations (7) and (8) with Young's equation is given:

$$
(1+\cos \theta) \gamma_{l}=2\left(\sqrt{\gamma_{l}^{L W} \gamma_{s}^{L W}}+\sqrt{\gamma_{l}^{+} \gamma_{s}^{-}} \sqrt{\gamma_{l}^{-} \gamma_{s}^{+}}\right)
$$

The vOCG approach to the evaluation of acid-base properties of solid surfaces by contact measurements is undoubtedly the most important development of present-day interface science [13-16,17].

\section{Experimental}

\subsection{Materials}

As a polyolefin sheets $(120 \times 120 \times 2 \mathrm{~mm})$ tested in this study has been prepared: Polyethylene (PE-LDPE Bralen RA 2-63), $5 \mathrm{~min}$ at temperature of $180^{\circ} \mathrm{C}$, polypropylene (PP-Chemopetrol N 159-93), $5 \mathrm{~min}$ at temperature of $227^{\circ} \mathrm{C}$ and polystyrene (PS-Krasten 154 ), 5 min at temperature of $200^{\circ} \mathrm{C}$ by injection molding machine.

\subsection{Methods}

Plasma surface treatment was performed in reactor built by Vakuum Praha at the Institute of Physics and Material Engineering, Thomas Bata in Zlin. Radio-frequency discharge was excited at $13.56 \mathrm{MHz}$ with inner diameter of $80 \mathrm{~mm}$ equipped with plain parallel electrodes placed in the $50 \mathrm{~mm}$ distance. Operating pressure was $0.5 \times 10^{-3}$ Ba. Air was used as a discharge gas. Apparatus was consisted of rotary and diffusion vacuum pump, vacuum meter TPG 215 (Pfeiffer), mass flow controller (Cole 
Palmer). The samples of PP, PE, PS were exposed in the following time range $0-360 \mathrm{~s}$. The time between exposition and experimental measurement was not longer than 30 min.

The magnitude of the contact angle, $\theta$, between the liquid and solid can be determined by various methods. The selection of the method to be used depends on the character of the studied sample system, as well as on the accuracy required. The two most common methods are: a static measurement of sessile drop by See System with CCD camera and a dynamic Wilhelmy plate method. The static contact angle of wetting was measured by a sessile drop resting on a flat solid surface using a video camera equipped interfaced to a computer with image-analysis software to determine the tangent value precisely on the captured image [8].

The dynamic contact angle of wetting was measured on Tensiometre K112 (Krüss, GmbH, Hamburg) with LabDesk system. The measurement was carried out at the constant temperature $\left(23^{\circ} \mathrm{C}\right)$. Advancing $\theta_{A}$ and receding $\theta_{R}$ contact angles were obtained. The surface heterogeneity gives rise to contact angle hysteresis, that is a difference between the advancing and receding contact angles [18]. For the calculation of surface free energy was considered only advancing angle. Deionised distilled water (conductivity of $0.07 \times 10^{-4} \mathrm{~S} / \mathrm{m}$ ) (Watek Demiwa 3ROS, Czech Republic), glycerole (98\%, Sigma-Aldrich, USA) and ethylene glycol (98\%, Sigma-Aldrich, USA) were used as a testing liquids for the determination of dispersive and polar components of SFE as well as for Lifshitz-van der Waals contributions. The particular parts values of surface tension of testing liquid are shown in Table 1.

\section{Results and Discussion}

It was found in this study that the glow-discharge air plasma treatment has a strong effect on wettability of synthetic polymers. This fact can be illustrated by observed changes of the magnitudes of the measured contact angles of wetting between the wetting testing liquid and a tested solid interface (synthetic polymer) as shown in Figure $\mathbf{1}$ and data given in Tables $\mathbf{2}$ and $\mathbf{3}$.

Table 1. Surface tensions and components $\left(\mathrm{mJ} \cdot \mathrm{m}^{-2}\right)$ suggested by vOCG [16].

\begin{tabular}{lcccc}
\hline Wetting liquid & $\gamma_{L V}$ & $\gamma_{L V}^{+}$ & $\gamma_{L V}^{-}$ & $\gamma_{L V}^{L W}$ \\
\hline Deionised distilled water & 72.8 & 25.5 & 25.5 & 21.8 \\
Glycerole $\left(\mathrm{C}_{3} \mathrm{H}_{8} \mathrm{O}_{3}\right)$ & 64.0 & 3.92 & 57.4 & 34.0 \\
Ethylene glycol $\left(\mathrm{C}_{2} \mathrm{H}_{6} \mathrm{O}_{2}\right)$ & 48.0 & 1.92 & 47.0 & 29.0 \\
\hline
\end{tabular}

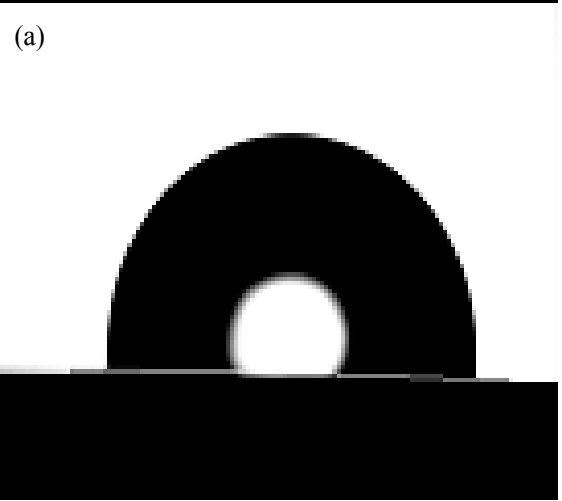

(b)

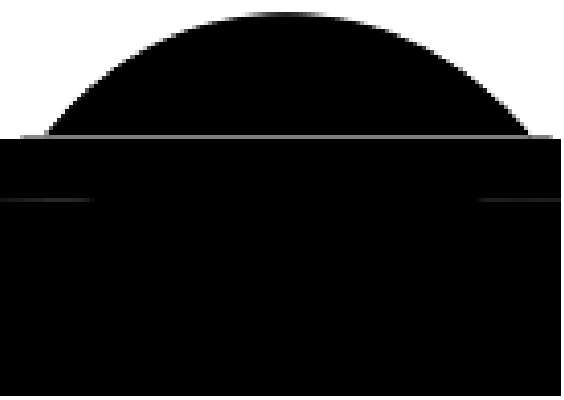

Figure 1. Water drop profiles on virgin PE (a) and PE treated with air plasma (b).

Table 2. Air plasma treatment time dependence of the observed static contact angles of wetting of untreated and plasma treated polymers (PE, PP, PS) as followed by sessile drop method. The values of contact angles are averages of results obtained from a set of $\mathbf{1 0}$ measurements.

\begin{tabular}{|c|c|c|c|c|c|c|c|c|c|}
\hline \multirow{2}{*}{$\mathrm{t}(\mathrm{s})$} & \multicolumn{3}{|c|}{ W } & \multicolumn{3}{|c|}{ G } & \multicolumn{3}{|c|}{ EG } \\
\hline & $\mathrm{PE}$ & PP & PS & $\mathrm{PE}$ & PP & PS & PE & PP & PS \\
\hline 0 & $87.2 \pm 1.0$ & $72.6 \pm 2.9$ & $93.4 \pm 1.9$ & $77.1 \pm 4.0$ & $70.6 \pm 1.0$ & $83.8 \pm 1.5$ & PE & PP & PS \\
\hline 30 & $52.6 \pm 0.7$ & $51.4 \pm 2.1$ & $29.0 \pm 2.0$ & $46.1 \pm 0.5$ & $50.5 \pm 2.1$ & $14.5 \pm 0.8$ & $61.9 \pm 0.9$ & $61.5 \pm 1.0$ & $42.1 \pm 0.7$ \\
\hline 120 & $41.7 \pm 2.2$ & $47.5 \pm 0.7$ & $9.7 \pm 0.5$ & $39.3 \pm 2.6$ & $48.4 \pm 1.4$ & $19.1 \pm 1.8$ & $26.9 \pm 1.1$ & $32.0 \pm 0.3$ & $13.7 \pm 0.8$ \\
\hline 360 & $58.6 \pm 1.0$ & $51.2 \pm 1.3$ & $11.8 \pm 0.9$ & $55.2 \pm 1.1$ & $51.0 \pm 1.8$ & $10.3 \pm 1.0$ & $27.6 \pm 0.6$ & $25.2 \pm 0.6$ & $10.2 \pm 0.8$ \\
\hline
\end{tabular}


Table 3. Air plasma treatment time dependence of the observed dynamic contact angles of untreated and plasma treated polymers (PE, PP, PS) as followed by Wilhelmy plate method.

\begin{tabular}{|c|c|c|c|c|c|c|}
\hline \multirow{3}{*}{$\mathrm{t}(\mathrm{s})$} & \multicolumn{6}{|c|}{ W } \\
\hline & \multicolumn{2}{|c|}{$\mathrm{PE}$} & \multicolumn{2}{|c|}{ PP } & \multicolumn{2}{|c|}{ PS } \\
\hline & $\theta_{A}\left[{ }^{\circ}\right]$ & $\theta_{R}\left[{ }^{\circ}\right]$ & $\theta_{A}\left[{ }^{\circ}\right]$ & $\theta_{R}\left[{ }^{\circ}\right]$ & $\theta_{A}\left[^{\circ}\right]$ & $\theta_{R}\left[^{\circ}\right]$ \\
\hline 0 & $87.8 \pm 1.8$ & $51.1 \pm 2.6$ & $84.6 \pm 2.6$ & $29.6 \pm 2.1$ & $88.7 \pm 2.7$ & $39.0 \pm 2.6$ \\
\hline 30 & $59.9 \pm 0.6$ & $40.8 \pm 0.5$ & $64.1 \pm 1.3$ & $19.0 \pm 4.0$ & $43.8 \pm 3.1$ & $27.6 \pm 3.6$ \\
\hline 120 & $57.0 \pm 0.8$ & $34.9 \pm 2.0$ & $61.4 \pm 0.7$ & $34.0 \pm 1.5$ & $43.2 \pm 2.3$ & $29.9 \pm 1.9$ \\
\hline \multirow[t]{2}{*}{360} & $58.6 \pm 0.5$ & $30.7 \pm 1.9$ & $59.0 \pm 2.1$ & $38.0 \pm 1.4$ & $43.8 \pm 2.2$ & $30.0 \pm 2.0$ \\
\hline & \multicolumn{6}{|c|}{$\mathrm{G}$} \\
\hline \multirow[t]{2}{*}{$\mathrm{t}(\mathrm{s})$} & \multicolumn{2}{|c|}{$\mathrm{PE}$} & \multicolumn{2}{|c|}{ PP } & \multicolumn{2}{|c|}{ PS } \\
\hline & $\theta_{A}\left[{ }^{\circ}\right]$ & $\theta_{R}\left[^{\circ}\right]$ & $\theta_{A}\left[{ }^{\circ}\right]$ & $\theta_{R}\left[^{\circ}\right]$ & $\theta_{A}\left[{ }^{\circ}\right]$ & $\theta_{R}\left[^{\circ}\right]$ \\
\hline 0 & $87.7 \pm 1.5$ & $47.5 \pm 3.7$ & $83.7 \pm 1.0$ & $39.1 \pm 4.2$ & $84.6 \pm 0.5$ & $42.7 \pm 1.7$ \\
\hline 30 & $73.0 \pm 1.4$ & $22.8 \pm 2.7$ & $72.7 \pm 0.8$ & $33.5 \pm 0.4$ & $55.3 \pm 0.8$ & $23.8 \pm 0.7$ \\
\hline 120 & $75.4 \pm 0.4$ & $19.1 \pm 0.6$ & $79.2 \pm 1.4$ & $33.6 \pm 1.5$ & $52.4 \pm 2.2$ & $22.5 \pm 2.7$ \\
\hline \multirow[t]{2}{*}{360} & $73.0 \pm 1.6$ & $19.3 \pm 1.8$ & $79.9 \pm 0.3$ & $29.3 \pm 1.6$ & $55.4 \pm 3.7$ & $23.1 \pm 1.3$ \\
\hline & \multicolumn{6}{|c|}{ EG } \\
\hline \multirow[t]{2}{*}{$\mathrm{t}(\mathrm{s})$} & \multicolumn{2}{|c|}{$\mathrm{PE}$} & \multicolumn{2}{|c|}{$\mathrm{PP}$} & \multicolumn{2}{|c|}{ PS } \\
\hline & $\theta_{A}\left[^{\circ}\right]$ & $\theta_{R}\left[{ }^{\circ}\right]$ & $\theta_{A}\left[{ }^{\circ}\right]$ & $\theta_{R}\left[^{\circ}\right]$ & $\theta_{A}\left[^{\circ}\right]$ & $\theta_{R}\left[{ }^{\circ}\right]$ \\
\hline 0 & $66.8 \pm 2.1$ & $26.9 \pm 2.2$ & $60.9 \pm 1.4$ & $31.1 \pm 3.1$ & $64.5 \pm 0.7$ & $26.7 \pm 1.6$ \\
\hline 30 & $36.1 \pm 1.5$ & $17.3 \pm 1.9$ & $36.4 \pm 2.3$ & $13.7 \pm 2.8$ & $21.5 \pm 1.2$ & $12.0 \pm 1.1$ \\
\hline 120 & $30.7 \pm 1.4$ & $16.0 \pm 1.3$ & $32.7 \pm 3.0$ & $17.5 \pm 1.5$ & $19.3 \pm 0.5$ & $13.4 \pm 1.2$ \\
\hline 360 & $21.7 \pm 3.4$ & $12.1 \pm 1.0$ & $29.9 \pm 2.5$ & $17.0 \pm 0.8$ & $17.0 \pm 1.6$ & $10.9 \pm 1.1$ \\
\hline
\end{tabular}

As given in Table 2, the increasing of plasma treatment time in the time frame of 0 to $120 \mathrm{~s}$ was reflected in decreasing values of measured contact angles. The plasma modification of non-polar polymer material leads to incorporation of polar function groups onto its surface such as $-\mathrm{COOH},-\mathrm{C}=\mathrm{O}$, $-\mathrm{OH}$ as confirmed earlier by XPS analysis [13]. In contrary to the latter decrease with increasing plasma treatment time exceeding $120 \mathrm{~s}$ the increase of the contact angles of wetting was found in this study. This phenomenon is well known for plasma treated synthetic polymers and is caused by proceeding process of ablation of the activated polymer top layer and gradual re-exposure of the original non-treated polymer surface. The values of total SFE were determined (see Tables 4 and 5) from both static and dynamic contact angle measurements for the following series of testing liquids: Water (W), Glycerol (G) and Ethylene glycol (EG) (see Table 1). It was found that with prolonged treatment time the total surface free energy of PE was two times increased from $23 \mathrm{~mJ} / \mathrm{m}^{2}$ to $45 \mathrm{~mJ} / \mathrm{m}^{2}$ after $360 \mathrm{~s}$ plasma treatment time (calculated for $\mathrm{W}$ and $\mathrm{EG}$ as wetting liquids). Similar effect was found for all studied polymers. With respect to the dispersive and polar components of the total surface free energy the vigorous effect was found for polar component, for which it was increased from $7 \mathrm{~mJ} / \mathrm{m}^{2}$ to $20 \mathrm{~mJ} / \mathrm{m}^{2}$. 
Table 4. Surface free energy and its components of the untreated and plasma treated polymers calculated by Fowkes and vOCG methods as followed by static sessile drop technique.

\begin{tabular}{|c|c|c|c|c|c|c|c|c|c|}
\hline \multirow{2}{*}{$\frac{\text { Sample }}{\text { Plasma treatment }}$} & \multirow{2}{*}{ Liquid-liquid pairs $^{\mathrm{a}}$} & \multicolumn{3}{|c|}{ Fowkes } & \multicolumn{5}{|c|}{ van Oss, Chaudhury and Good } \\
\hline & & $\gamma_{s}^{D}$ & $\gamma_{s}^{P}$ & $\gamma_{s}$ & $\gamma_{s}^{+}$ & $\gamma_{s}^{-}$ & $\gamma_{s}^{A B}$ & $\gamma_{s}^{L W}$ & $\gamma_{s}$ \\
\hline \multirow[t]{3}{*}{ Untreated PE } & $\mathrm{W} / \mathrm{G}$ & 18.85 & 6.29 & 25.14 & 0.29 & 2.08 & 1.55 & 28.34 & 29.89 \\
\hline & $\mathrm{W} / \mathrm{EG}$ & 20.88 & 5.56 & 26.44 & & & & & \\
\hline & G/EG & 23.91 & 3.67 & 27.58 & & & & & \\
\hline \multirow[t]{3}{*}{ air $30 \mathrm{~s}$} & $\mathrm{~W} / \mathrm{G}$ & 17.23 & 30.02 & 47.25 & 0.43 & 10.12 & 4.16 & 43.48 & 47.64 \\
\hline & W/EG & 16.58 & 30.59 & 47.17 & & & & & \\
\hline & $\mathrm{G} / \mathrm{EG}$ & 15.69 & 32.31 & 48.00 & & & & & \\
\hline \multirow[t]{3}{*}{ air $120 \mathrm{~s}$} & $\mathrm{~W} / \mathrm{G}$ & 12.93 & 42.93 & 55.86 & 0.14 & 14.67 & 2.89 & 45.52 & 48.41 \\
\hline & W/EG & 9.33 & 47.69 & 57.02 & & & & & \\
\hline & $\mathrm{G} / \mathrm{EG}$ & 5.27 & 63.31 & 68.57 & & & & & \\
\hline \multirow[t]{3}{*}{ air $360 \mathrm{~s}$} & $\mathrm{~W} / \mathrm{G}$ & 12.18 & 29.93 & 42.11 & 3.76 & 9.58 & 12.00 & 27.03 & 39.04 \\
\hline & W/EG & 23.30 & 21.13 & 44.43 & & & & & \\
\hline & $\mathrm{G} / \mathrm{EG}$ & 44.93 & 4.01 & 48.93 & & & & & \\
\hline \multirow[t]{3}{*}{ Untreated PP } & $\mathrm{W} / \mathrm{G}$ & 8.13 & 22.62 & 30.76 & 0.42 & 7.60 & 3.58 & 24.28 & 27.85 \\
\hline & W/EG & 8.25 & 22.5 & 30.75 & & & & & \\
\hline & $\mathrm{G} / \mathrm{EG}$ & 8.41 & 22.13 & 30.54 & & & & & \\
\hline \multirow[t]{3}{*}{ air $30 \mathrm{~s}$} & $\mathrm{~W} / \mathrm{G}$ & 10.00 & 38.56 & 48.56 & 1.50 & 12.79 & 8.75 & 32.01 & 40.75 \\
\hline & W/EG & 15.65 & 32.38 & 48.03 & & & & & \\
\hline & $\mathrm{G} / \mathrm{EG}$ & 17.81 & 25.67 & 43.48 & & & & & \\
\hline \multirow[t]{3}{*}{ air $120 \mathrm{~s}$} & $\mathrm{~W} / \mathrm{G}$ & 8.57 & 43.91 & 52.48 & 2.50 & 14.43 & 12.00 & 29.54 & 41.53 \\
\hline & W/EG & 13.7 & 37.47 & 51.16 & & & & & \\
\hline & $\mathrm{G} / \mathrm{EG}$ & 22.89 & 21.36 & 44.25 & & & & & \\
\hline \multirow[t]{3}{*}{ air $360 \mathrm{~s}$} & $\mathrm{~W} / \mathrm{G}$ & 9.22 & 39.76 & 48.98 & 1.81 & 13.14 & 9.76 & 30.37 & 40.13 \\
\hline & W/EG & 12.95 & 35.26 & 48.21 & & & & & \\
\hline & $\mathrm{G} / \mathrm{EG}$ & 19.25 & 23.49 & 42.74 & & & & & \\
\hline Untreated PS & $\mathrm{W} / \mathrm{G}$ & 16.35 & 4.63 & 20.98 & 11.81 & 1.1 & 7.20 & 10.22 & 17.42 \\
\hline \multirow[t]{3}{*}{ air $30 \mathrm{~s}$} & $\mathrm{~W} / \mathrm{G}$ & 22.54 & 41.62 & 64.15 & & & & & \\
\hline & W/EG & 8.12 & 59.16 & 67.28 & & & & & \\
\hline & G/EG & 0.04 & 129.32 & 129.35 & & & & & \\
\hline \multirow[t]{3}{*}{ air $120 \mathrm{~s}$} & $\mathrm{~W} / \mathrm{G}$ & 9.60 & 65.54 & 75.14 & 0.06 & 22.54 & 2.25 & 50.73 & 52.98 \\
\hline & W/EG & 4.74 & 75.65 & 80.39 & & & & & \\
\hline & $\mathrm{G} / \mathrm{EG}$ & 0.78 & 109.94 & 110.72 & & & & & \\
\hline \multirow[t]{3}{*}{ air $360 \mathrm{~s}$} & $\mathrm{~W} / \mathrm{G}$ & 13.82 & 58.61 & 72.43 & & & & & \\
\hline & W/EG & 5.38 & 73.43 & 78.82 & & & & & \\
\hline & $\mathrm{G} / \mathrm{EG}$ & 0.13 & 127.23 & 127.36 & & & & & \\
\hline
\end{tabular}

${ }^{\mathrm{a}} \mathrm{G}$ : Glycerol; EG: Ethylene glycol; W: Water. 
Table 5. Surface free energy and its components of the untreated and plasma treated polymers calculated by Fowkes and vOCG methods as followed by dynamic Wilhelmy plate technique.

\begin{tabular}{|c|c|c|c|c|c|c|c|c|c|}
\hline \multirow{2}{*}{$\begin{array}{c}\text { Sample } \\
\text { Plasma treatment }\end{array}$} & \multirow[t]{2}{*}{ Liquid-liquid pairs ${ }^{\mathrm{a}}$} & \multicolumn{3}{|c|}{ Fowkes } & \multicolumn{5}{|c|}{ van Oss, Chaudhury and Good } \\
\hline & & $\gamma_{s}^{D}$ & $\gamma_{s}^{P}$ & $\gamma_{s}$ & $\gamma_{s}^{+}$ & $\gamma_{s}^{-}$ & $\gamma_{s}^{A B}$ & $\gamma_{s}^{L W}$ & $\gamma_{s}$ \\
\hline \multirow[t]{2}{*}{ Untreated PE } & $\mathrm{W} / \mathrm{G}$ & 3.76 & 16.20 & 19.96 & 5.87 & 4.91 & 10.73 & 6.92 & 17.65 \\
\hline & W/EG & 16.16 & 7.10 & 23.26 & & & & & \\
\hline air $30 \mathrm{~s}$ & W/EG & 17.08 & 24.51 & 41.60 & 23.86 & 17.97 & 41.41 & 1.16 & 42.57 \\
\hline air $120 \mathrm{~s}$ & W/EG & 18.08 & 25.94 & 44.02 & & & & & \\
\hline \multirow[t]{2}{*}{ air $360 \mathrm{~s}$} & W/EG & 24.77 & 20.24 & 45.01 & 34.75 & 18.69 & 50.97 & 0.16 & 51.13 \\
\hline & G/EG & 43.21 & 5.24 & 48.45 & & & & & \\
\hline \multirow[t]{2}{*}{ Untreated PP } & $\mathrm{W} / \mathrm{G}$ & 4.99 & 16.95 & 21.93 & 6.21 & 5.13 & 11.29 & 8.60 & 19.88 \\
\hline & W/EG & 19.16 & 7.37 & 26.53 & & & & & \\
\hline \multirow[t]{2}{*}{ air $30 \mathrm{~s}$} & $\mathrm{~W} / \mathrm{G}$ & 0.52 & 46.93 & 47.45 & 19.27 & 14.08 & 32.94 & 3.06 & 36.00 \\
\hline & W/EG & 20.80 & 18.85 & 39.65 & & & & & \\
\hline air $120 \mathrm{~s}$ & $\mathrm{G} / \mathrm{EG}$ & 20.83 & 20.73 & 41.56 & & & & & \\
\hline \multirow[t]{2}{*}{ air $360 \mathrm{~s}$} & W/EG & 20.39 & 22.75 & 43.14 & & & & & \\
\hline & $\mathrm{G} / \mathrm{EG}$ & 47.43 & 2.21 & 49.65 & & & & & \\
\hline \multirow[t]{3}{*}{ Untreated PS } & $\mathrm{W} / \mathrm{G}$ & 8.24 & 11.12 & 19.37 & 3.43 & 3.40 & 6.83 & 12.48 & 19.31 \\
\hline & W/EG & 19.58 & 5.38 & 24.96 & & & & & \\
\hline & $\mathrm{W} / \mathrm{G}$ & 1.14 & 65.24 & 66.38 & & & & & \\
\hline \multirow[t]{3}{*}{ air $30 \mathrm{~s}$} & W/EG & 12.85 & 41.37 & 54.22 & 11.25 & 20.61 & 30.45 & 10.97 & 41.43 \\
\hline & $\mathrm{G} / \mathrm{EG}$ & 50.61 & 2.40 & 53.01 & & & & & \\
\hline & $\mathrm{W} / \mathrm{G}$ & 2.39 & 60.86 & 63.25 & & & & & \\
\hline \multirow[t]{3}{*}{ air $120 \mathrm{~s}$} & W/EG & 13.27 & 41.35 & 54.63 & 8.62 & 19.39 & 25.86 & 15.10 & 40.97 \\
\hline & $\mathrm{G} / \mathrm{EG}$ & 43.33 & 5.59 & 48.92 & & & & & \\
\hline & $\mathrm{W} / \mathrm{G}$ & 1.10 & 65.45 & 66.55 & & & & & \\
\hline \multirow[t]{2}{*}{ air $360 \mathrm{~s}$} & W/EG & 14.40 & 39.63 & 54.03 & 12.70 & 20.55 & 32.32 & 10.12 & 42.43 \\
\hline & $\mathrm{G} / \mathrm{EG}$ & 23.71 & 23.11 & 46.83 & & & & & \\
\hline
\end{tabular}

${ }^{\mathrm{a}} \mathrm{G}$ : Glycerol; EG: Ethylene glycol; W: Water.

\section{Conclusion}

The focus of this paper was on the study of surface properties of selected synthetic polymers (PE, PP, PS) and their modification by glow discharge air plasma treatment. Two different approaches for calculation of the surface free energy and its components were employed using observed static and dynamic contact angles of wetting data (Fowkes approach and van Oss, Chaudhury and Good (vOCG) approach). It was found that both approaches are applicable for determination of surface free energy of polymer materials and they are capable to follow the changes induced by plasma modification. The results show that improper selection of testing probe liq- uid pairs and triplets can easily mislead into drawing inaccurate and different conclusions as confirmed earlier by Kwok $[13,16]$. Generally, it is possible to conclude that plasma treatment has a strong effect on the change of surface chemistry as well as topology which is reflected in the increased integral quantity known as wettability of polymer materials.

\section{Acknowledgements}

This article was created with support of Operational Program Research and Development for Innovations cofunded by European Regional Development Fund (ERDF) and national budget of Czech Republic within the frame- 
work of the Centre of Polymer Systems project (reg. number CZ.1.05/2.1.00/03.0111) and to the Tomas Bata University in Zlin Internal Grant Agency project no. IGA/FT/2012/020.

\section{REFERENCES}

[1] K. Grundke, P. Uhlmann, T. Gietzelt, B. Redlich and H. Jacobasch, "Studies on the Wetting Behaviour of Polymer Melts on Solid Surfaces Using the Wilhelmy Balance Method," Colloids and Surfaces A: Physicochemical and Engineering Aspects, Vol. A116, No. 1-2, 1996, pp. 93104.

[2] H. Y. Erbil, "Surface Chemistry of Solid and Liquid Interfaces," Blackwell Publishing, Oxford, 2006.

[3] P. C. Hiemenz and R. Rjagopalan, "Principles of Colloid and Surface Chemistry," 3rd Edition, Marcel Dekker, New York, 1997.

[4] F. Poncil-Epaillard, B. Chevet and J.-C. Brosse, "Functionalization of Polypropylene by a Microwave (433 MHz) Cold Plasma of Carbon Dioxide. Surface Modification or Surface Degradation?" European Polymer Journal, Vol. 26, No. 3, 1990, pp. 333-339. doi:10.1016/0014-3057(90)90250-8

[5] A. W. Adamson and A. P. Gast, "Physical Chemistry of Surfaces," 6th Edition, John Wiley \& Sons, Los Angeles, 1997.

[6] J. S. Kim, R. H. Friend and F. Cacialli, "Surface Wetting Properties of Treated Indium Tin Oxide Anodes for Polymer Light-Emitting Diodes," Synthetic Metals, Vol. 2000, No. 111-112, 2000, pp. 369-372. doi:10.1016/S0379-6779(99)00329-X

[7] C. M. Chan, "Polymer Surface Modification and Characterization," Hanser/Gardner, Munich, 1994.

[8] K. S. Birdi, "Handbook of Surface and Colloid Chemistry," 3rd Edition, CRC Press, Boca Raton, 2008. doi:10.1201/9781420007206

[9] L. Lapčík, M. Fraštík and B. Lapčíková, "Imping Jet Study of the Deposition of Colloidal Particles on Modified Polycarbonate and Poly (Ethylene Terephthalate) Surfaces," Internal Journal of Heat and Mass Transfer,
Vol. 55, No. 5-6, 2012, pp. 1513-1518. doi:10.1016/j.ijheatmasstransfer.2011.11.002

[10] R. Gajdošíková, B. Lapčíková and L. Lapčík, "Surface Phenomena and Wetting of Porous Solids," Physical Chemistry, Vol. 6, No. 3, 2011, pp. 146-162.

[11] P. C. Hiemenz, "Principles of Colloid and Surface Chemistry," Marcel Dekker, Inc., New York, 1986.

[12] Z. Zhong, S. Yin, C. Liu, Y. Zhong, W. Zhang, D. Shi and C. Wang, "Surface Energy for Electroluminescent Polymers and Indium-Tin-Oxide," Applied Surface Science, Vol. 207, No. 1-4, 2003, pp. 183-189. doi:10.1016/S0169-4332(02)01328-4

[13] D. Y. Kwok and A. W. Neumann, "Contact Angle Measurement and Contact Angle Interpretation," Advances in Colloid Interface Science, Vol. 81, No. 3, 1999, pp. 167249. doi:10.1016/S0001-8686(98)00087-6

[14] M. Zenkiewicz, "Methods for the Calculation of Surface Free Energy of Solids," Journal of Achievements in Materials and Manufacturing Engineering (JAMME), Vol. 24, No. 1, 2007, pp. 1-9.

[15] C. J. van Oss, M. K. Chaundry and R. J. Good, "Interfacial Lifshitz-van der Waals and Polar Interaction in Macroscopic Systems," Chemical Reviews, Vol. 88, No. 6, 1988, pp. 927-941. doi:10.1021/cr00088a006

[16] D. Y. Kwok, "The Usefulness of the Lifshitz-van der Waals: Acid-Base Approach for Surface Tension Components and Interfacial Tensions," Colloids and Surfaces A: Physicochemical and Engineering Aspects, Vol. 156, No. 1-3, 1999, pp. 191-200. doi:10.1016/S0927-7757(99)00070-9

[17] L. H. Lee, "Relevance of Film Pressures to Interfacial Tension, Miscibility of Liquids, and Lewis Acid-Base Approach," Journal of Colloid and Interface Science, Vol. 214, No. 1, 1999, pp. 64-78. doi:10.1006/jcis.1999.6165

[18] M. Strobel, C. S. Lyons and K. L. Mittal, "Plasma Surface Modification of Polymers: Relevance to Adhesion," VSP, Utrech, 1994.

[19] K. Holmberg, B. Jonsson, B. Kronberg and B. Lindmann, "Surfactants and Polymers in Aquenous Solution," 2nd Edition, Wiley, New York, 2003. 